\title{
Axonal Activation-Induced Calcium Transients in Myelinating Schwann Cells, Sources, and Mechanisms
}

\author{
V. Lev-Ram ${ }^{1}$ and M. H. Ellisman ${ }^{2}$ \\ 'Department of Pharmacology and ${ }^{2}$ Department of Neurosciences and the San Diego Microscopy and Imaging \\ Resource, University of California-San Diego, La Jolla, California 92093-0608
}

\begin{abstract}
We have investigated the role of myelinating glia in events associated with propagation of the action potential at nodes of Ranvier using combinations of optical and electrophysiological recording methods. Calcium transients were observed in Schwann cells by fluorescent imaging of the nodal complex of fibers loaded with the calcium-sensitive dye fluo3-AM. To follow $\left[\mathrm{Ca}^{2+}\right]_{i}$ changes associated with neuronal activity at the node of Ranvier, nerves loaded with fluo3 were imaged during axonal activation using laser-scanning confocal microscopy. To elucidate sources of $\left[\mathrm{Ca}^{2+}\right]_{i}$ transients, we tested the effects of drugs known to alter $\left[\mathrm{Ca}^{2+}\right]_{i}\left[\mathrm{Ca}^{2+}\right]_{i}$ transients in Schwann cells were observed in response to axonal activation and these were subsequently blocked by ryanodine if ryanodine was present during a previous $\left[\mathrm{Ca}^{2+}\right]_{i}$ transient. Bath applications of caffeine induced $\left[\mathrm{Ca}^{2+}\right]_{t}$ transients which could be blocked by ryanodine. These findings indicate that calcium-activated calcium release occurs in Schwann cells in response to impulse activity.
\end{abstract}

[Key words: Schwann cells, node of Ranvier, calcium imaging, confocal microscopy, ryanodine]

From early anatomical observations of myelinated nerves, Ranvier (1878) speculated the function of myelin and nodes in axonal conduction. However, the functions proposed by both Ranvier and others later were passive and did not include dynamic interactions between axons and their myelinating cells. Thus, the myelin sheath has been thought to protect the axon against compression and also to provide an electrically insulative barrier. This insulation allows for an increase in conduction velocity and reduction in the metabolic cost of impulse conduction by increasing the electrical impedance between the axoplasm and the extracellular fluid, thereby requiring only segmental amplification of the nerve impulse. This manner of conduction is called saltatory and was first hypothesized by Lillie in 1925. Beyond this now well established concept of providing for saltatory conduction, there are numerous studies, both anatomical and physiological (Murray and Steck, 1984; Endres et al., 1986; Lev-

\footnotetext{
Received Mar. 4, 1994; revised Sept. 26, 1994; accepted Oct. 12, 1994

This research was supported by NIH grants to M. H. Ellisman (NS14718 and RR04050) and R. Y. Tsien (NS27177). We gratefully acknowledge the efforts of Drs. S. Steffenson and S. Raymond, who contributed to the initial electrophysiological studies, Dr. R. Y. Tsien for helpful advice and support, S. Lamont for software development, and Dr. M. Martone for comments on the manuscript.

Correspondence should be addressed to Dr. Varda Lev-Ram at the above address.

Copyright $(1995$ Society for Neuroscience $\quad 0270-6474 / 95 / 152628-10 \$ 05.00 / 0$
}

Ramn and Grinvald, 1986, 1987; Wurtz and Ellisman, 1986, 1987; Carley and Raymond, 1987; Halter and Clark, 1991), that support the idea that the axon/myelin/glial cell ensemble or "nodal complex" operates in an integrated manner during conduction of the nerve impulse. The components of the nodal complex that we suspect interact during axonal activity include the axonal differentiation at the node together with adjacent paranodal terminations of the myelin sheath, and glial processes which invest the nodal gap and its substance. Since subtle physiological interactions between components or compartments of the nodal complex have been difficult to study with more traditional electrophysiological methods, we sought alternative methods with which to study these interactions.

The associations of cell processes at nodes of Ranvier are known to be sensitive to high-frequency activation (Wurtz and Ellisman, 1986), exposure to diagnostic ultrasound (Ellisman et al., 1987), demyelinative agents (Wilcy-Livingston and Ellisman, 1982, and others summarized in Dyck et al., 1993), and mechanical disturbances caused by the teasing of fibers required to isolate individual axons (Ranvier, 1878; Uhrik and Stampfli, 1981). In order to examine individual myelinated axons optically during stimulation we developed an in vitro preparation consisting of bundles of axons from frog sciatic nerve. These fibers were observed using fluorescent calciun indicator dye imaged by a laser-scanning confocal microscopy and Nomarski DIC optics. The preparation developed for the studies reported here allowed evaluation of physiological properties of nodes of Ranvier that have undergone less manipulation than commonly required for previous physiological work (Uhrik and Stampfli, 1981). Thus, the in vitro preparation presented in this report provides a unique facility to test hypotheses regarding the function of cell compartments at the node of Ranvier.

$\Lambda \mathrm{s}$ a framework to guide future experimentation, we present a model for nodal function that incorporates the observations of the present studies indicating active participation of myelinating glia in the normal functioning of the node of Ranvier. Briefly, this model embodies the hypothesis that the paranodal region of the ensheathing glial cell is responsible for potassium buffering. Potassium leaving the axon selectively passes into the paranodal loops instead of accumulating in the extracellular space. We also propose a role for cytoplasmic calcium fluctuations in nodal function.

\section{Materials and Methods}

Solutions. Frog Ringer's contained (in $\mathrm{mM}$ ) NaCl, 81.6; KCl, 2; $\mathrm{CaCl}_{2}$, 1.7; $\mathrm{MgCl}_{2}, 1.2 ; \mathrm{NaH}_{2} \mathrm{PO}_{4}, 1.2 ; \mathrm{NaHCO}_{3}, 25 ;$ and D-glucose, 3.3. The solution was bubbled before and during the experiment with humidified $95 \%$ air $5 \% \mathrm{CO}_{2}$ mixture. The $\mathrm{pH}$ was 7.4 . Experiments were performed 
at room temperature. For calcium-free Ringer's, $\mathrm{CaCl}_{2}$ was substituted with $\mathrm{MgCl}_{2}$ and $0.5 \mathrm{~mm}$ EGTA was added.

Sciatic nerve dissection. Whole sciatic nerve from decapitated and pithed Rana pipiens frogs ( $5-8 \mathrm{~cm}$ snout to vent length) was dissected from the lower tibiofibula to the spinal ganglia. The nerve was then placed in a chamber milled from Plexiglas with a coverslip glued to a window on the hottom, and submerged in cold oxygenated frog Ringer's solution. The nerve was desheathed, and the end (closer to the spinal cord) was aspirated into the cathodal stimulating suction electrode and stimulated through a silver-silver chloride wirc $2-3 \mathrm{~cm}$ away from the imaged area. The other end of the nerve was tied with surgical silk thread to a hook at the other end of the chamber in order to keep the nerve straight but not stretched. The nerve fibers at the center were gently separated so that a single fiber could be aspirated by a suction electrode and the electrophysiological responses of the stimulated nerve could be recorded. For imaging, this tiber was followed to the second or third node away from the suction electrode to observe a nondisrupted node. The nerve was then simultaneously imaged and electrically stimulated while electrophysiological responses were recorded. Reliable and repetitive calcium transients could be induced by stimulation (for 1-5 min) at frequencies of from $50 \mathrm{~Hz}$ to $100 \mathrm{~Hz}$. Frequencies at the lower end of this range (between 50 and $70 \mathrm{~Hz}$ ) were used for experimental paradigms designed to employ multiple stimulations in order to avoid exhausting the nerve. There were no significant qualitative differences between 50 and $70 \mathrm{~Hz}$ (data not shown). Nerves were perfused with fresh oxygenated frog Ringer's solution at a rate of $1 \mathrm{ml} / \mathrm{min}$ throughout all experiments. Drugs were introduced using the same perfusion system.

In initial experiments it was established that calcium transients could be observed in preparations teased to single fibers. However, the yield of healthy active fibers was much lower with the extensive teasing required to expose single fibers for several internodal lengths. Consequently, most of the work reported here was carried out on preparations in which the nerve was gently dissected to bundles of 10-20 fibers with the recording of electrical activity accomplished by monitoring the activity of the whole bundle. The ability of the laser-scanning confocal light microscopy to provide optical sectioning of such material allowed us to work with such "intact" bundles. This less perturbed preparation allowed for much more consistent and stable observations of the calcium transients than observed in the mechanically separated single fibers.

Calcium indicator dye loading. Fluo3-AM was made up by vigorously mixing $5 \mu \mathrm{l}(1 \mathrm{~mm})$ of dye solution in DMSO with $5 \mu$ l Pluronic F-127 (20\% in DMSO) and adding it into $1 \mathrm{ml}$ of frog Ringer's solution while agitating with a vortex mixer. The mixture was then diluted to a final concentration of $5 \mu \mathrm{M}$ and added to the suspended, desheathed nerve in its recording chamber. The recording chamber was then placed in a closed container and provided with a constant flow of humidified gas mixture $\left(95 \%\right.$ air $\left./ 5 \% \mathrm{CO}_{2}\right)$ to maintain proper oxygen supply and $\mathrm{pH}$ buffering. After $2 \mathrm{hr}$ of incubation the nerve was washed with fresh frog Ringer's solution and placed in the special recording stage for electrophysiological, imaging, and experimental manipulations.

Imaging and measurement of calcium transients. A Bio-Rad MRC600 laser-scanning confocal microscope was used for imaging of single fiber calcium transients and analysis of its subcellular localization. Time-lapse images of nerves loaded with fluo 3 via its AM ester form were imaged before, during, and after stimulation and drug application. The images were saved onto rewritable optical disc media. The images then were transferred to a Silicon Graphics workstation (R4000/ Crimson) over an Ethernet using NFS. Data analysis was conducted using B-TRACK software developed at the San Diego Microscopy and Imaging Resource by Stephan Lamont. This software allows tracking and quantitative analysis of multiple regions in the same field. The results are presented as Nomarski, pseudocolor images and graphs of the fluorescence fractional changes in time as a response to stimulation and/or drug application.

\section{Results}

Loading of sciatic nerve with the calcium indicator fluo3 via its $A M$ ester

To gain an understanding of the morphological changes induced in Schwann cells by axonal activity we examined Schwann cells loaded with calcium indicator dye during axonal stimulation. To observe changes in intracellular calcium concentrations
$\left(\left[\mathrm{Ca}^{2+}\right]_{i}\right)$, nerves were loaded with the calcium indicator fluo3 via its $\mathrm{AM}$ ester. This calcium indicator was chosen for several reasons. Most importantly, the quantum efficacy of fluo3 is relatively high and the signal-to-noise ratio can be greater than many of the other available calcium indicators. This allowed reliable data to be obtained with no frame averaging. Fluo3's excitation wavelength is in the visible region and thus its excitation results in less photodynamic damage during illumination periods. Moreover, it can be excited easily with the kryptonargon mixed gas laser or argon lasers of the Bio-Rad laser-scanning confocal microscope. The use of confocal microscopy for these experiments allowed the examination of nodes in bundles of fibers and the optical sectioning of areas of interest.

Somewhat serendipitously, loading the peripheral nerve with the AM ester dye resulted in dye accumulation in Schwann cells but not in the axon. The possibility that this selective staining was due to low calcium levels and therefore to nondetectable fluorescent levels in axons was tested by application of ionomycin or digitonin at the end of most of the experiments. This manipulation resulted in a saturating level of fluorescence in all Schwann cell cytoplasmic pockets but did not change the fluorescence level in axons. We assume that this loading pattern is a consequence of the structural relationship between the Schwann cell and the axon. The myelinating Schwann cell processes invest the axon and perhaps preclude dye access in the internodal, paranodal, and nodal regions. Observation of the stained nerve with the confocal microscope revealed fluorescence in the Schwann cell's paranodal loops as well as in its cell body, Schmidt-Lantermann clefts, and cytoplasmic pockets of the longitudinal incisors (Mugnaini et al., 1977) (Fig. 1). This selective loading of Schwann cells then served as a relatively specific stain and made it easier to define the location of associated calcium transients.

\section{Studies combining imaging of $\left[\mathrm{Ca}^{2+}\right]_{\mathrm{i}}$ transients from myelinating Schwann cells with electrophysiological recordings from the same fiber}

Lev-Ram and Grinvald (1987) recorded $\left[\mathrm{Ca}^{2+}\right]_{i}$ transients following axonal activation from rat optic nerve using fura 2 and a single photodetector. These $\left[\mathrm{Ca}^{2+}\right\rceil_{i}$ transients were composed of two components which could be separated into a fast component, probably arising from $\left[\mathrm{Ca}^{2+}\right]_{i}$ increase in axons, and a slower component which was described as "myelin associated." To follow up on these observations in a single node and to directly determine the spatial and cellular origin of the $\left[\mathrm{Ca}^{2+}\right]_{i}$ transients, the following series of experiments were performed.

$\left[\mathrm{Ca}^{2+}\right]_{i}$ transients of nerves loaded with fluo 3 were observed during nerve stimulation and recovery (Fig. 2). The fluorescence intensity is indicated by pseudocolors that are used to enhance the changes in brightness associated with the changes in $\left[\mathrm{Ca}^{2+}\right]_{i}$. Blue indicates a low fluorescent level. As $\left[\mathrm{Ca}^{2+}\right]_{i}$ rises, the fluorescence intensity increases and the color changes gradually to green and then to red. These colors do not reflect a quantitative scale. As a result of $20 \mathrm{~Hz}$ stimulation the fluorescence increases at the nodal area (arrowhead). Surprisingly, a rise in calcium was also detected in the outer Schwann cell cytoplasmic pockets. These are clearly revealed in the confocal optical section in the center of the fiber (upper left fiber) and in the lower right fiber where the optical sectioning slices through the outer loop only. The activity-associated rise in $\left[\mathrm{Ca}^{2+}\right]_{i}$ also occurred simultaneously in all these cytoplasmic pockets (Fig. $2 b-f$ ). When the stimulation has ceased and the fiber rested for only $5 \mathrm{~min}$, a 


\section{Transmitted DIC}
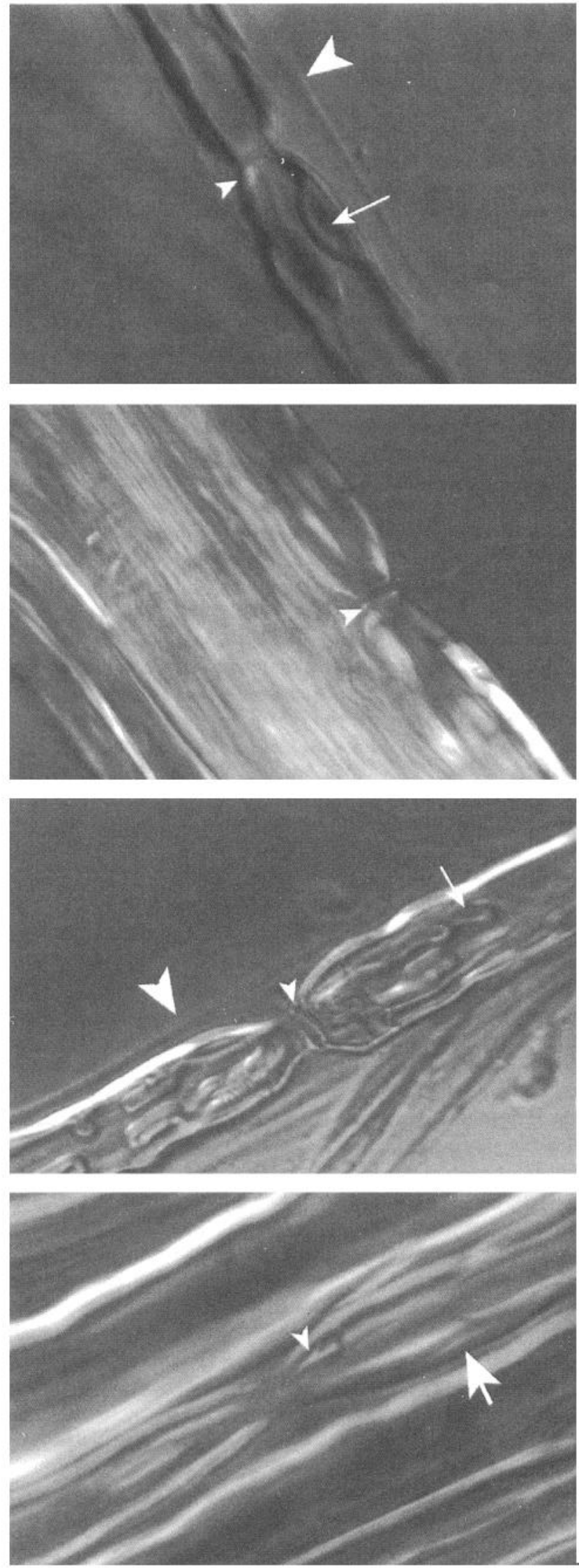

\section{Epi fluorescent}
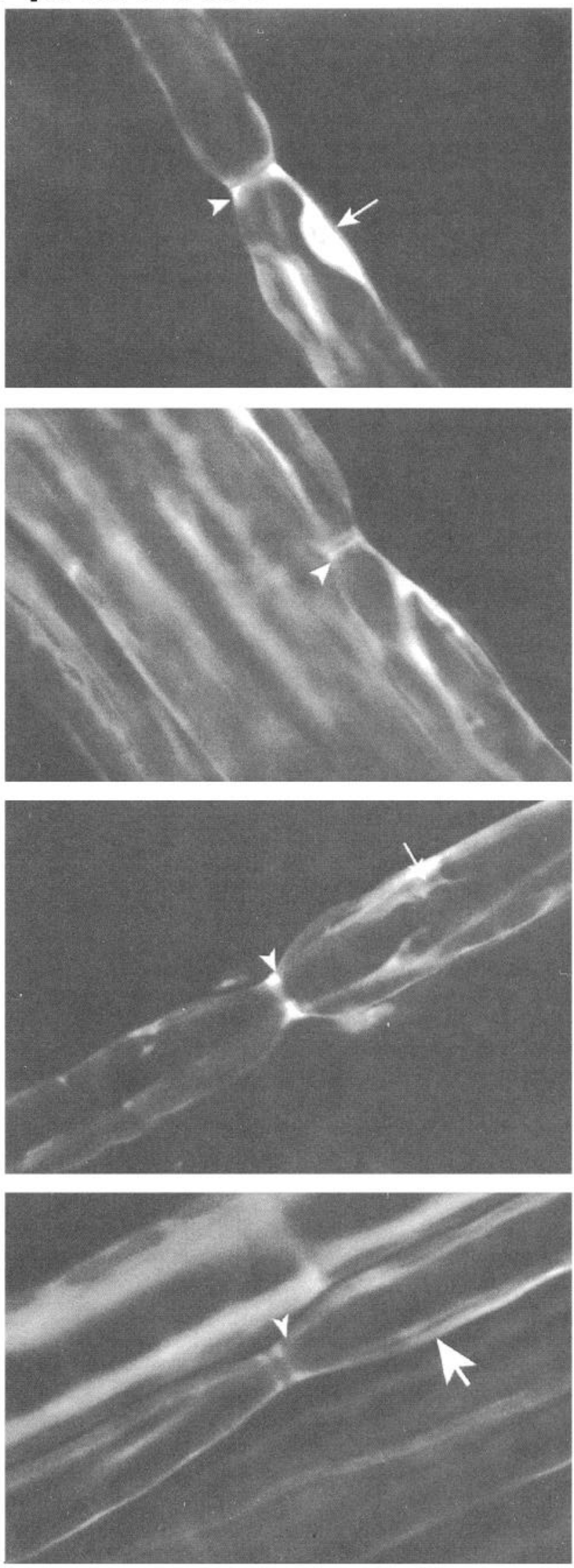
continued rise in the $\left[\mathrm{Ca}^{2+}\right]_{i}$ level was noted (Fig. $2 g$ ). After further recovery for a total of $21 \mathrm{~min}$ (Fig. $2 j$ ), the nerve was stimulated again at a higher frequency of $70 \mathrm{~Hz}$ (Fig. $2 k, l$ ). This time the rise in $\left[\mathrm{Ca}^{2+}\right]_{i}$ was more rapid and the recovery was faster upon cessation of stimulation (Fig. $2 m-o$ ). This may be due to the use of a shorter stimulation period $(2 \mathrm{~min})$. Comparison of results from several $(n=9)$ of these experiments indeed revealed that the recovery duration depends upon the duration and frequency of the stimulation. Figure $2 p$ presents a graphic summary of the data from the node of Ranvier shown at the center of the image. Note that the maximal fractional change in fluorescence is approximately $35 \%$. A change of this magnitude was typically observed for this activity-associated paranodal $\left[\mathrm{Ca}^{2+}\right]_{i}$ transient.

\section{Intracellular calcium stores in myelinating Schwann cells}

The $\left[\mathrm{Ca}^{2+}\right]_{i}$ transients that we observed in Schwann cells during axonal activity could arise from several sources. Calcium can enter the cells through plasma membrane voltage-dependent calcium channels, calcium exchangers, and/or it can be released from internal stores. To investigate the possible sources contributing to this activity-associated rise in calcium, several experimental approaches were taken. These included axonal activation at zero extracellular calcium and $0.5 \mathrm{mIM}$ EGTA, depletion of calcium from ryanodine-dependent calcium stores with caffeine, and depletion of calcium from $\mathrm{IP}_{3}$-dependent stores with thapsigargin.

Figure 3 represents an experiment $(n=4)$ which indicates that extracellular calcium is at least the initial source for the calcium transients in Schwann cells associated with axonal activation. In this experiment, a $3 \mathrm{~min} 70 \mathrm{~Hz}$ train of electrical stimulation was applied to the nerve. An increase is observed in response to this stimulation in the nodal area of a Schwann cell. When the bathing solution is changed to frog Ringer's without calcium and $0.5 \mathrm{mM}$ EGTA (Fig. 3B), another $\left[\mathrm{Ca}^{2+}\right]_{i}$ transient could not be induced by further stimulation. This indicates that at least the initial change in $\left[\mathrm{Ca}^{2+}\right]_{i}$ is from external sources. Figure $3 \mathrm{C}$ shows a $\left[\mathrm{Ca}^{2+}\right]_{i}$ transient induced by another $70 \mathrm{~Hz}$ stimulation after the bathing media was changed back to normal frog Ringer's solution. These results suggest the presence of calcium entry from an external source in this region of myelinating Schwann cells. This is consistent with the observations of Amedee and co-workers (1991), who determined voltage-dependent calcium channels to be present in myelinating Schwann cells in organotypic cultures of dorsal root ganglia using whole-cell patch-clamp recording methods.

In addition to these specific experiments on the importance of extracellular $\mathrm{Ca}^{2+}$ (depicted in Fig. 3), we conducted other experiments in which the elimination of extracellular $\mathrm{Ca}^{2}$ ' resulted in the loss of the activity-induced $\mathrm{Ca}^{2+}$ transient. These included studies in which the nerve was exposed to pharmacological manipulations after first establishing the absence of the activityinduced $\mathrm{Ca}^{2+}$ transient in the absence of external $\mathrm{Ca}^{2+}$, similar to those described below. Thus, the number of experiments which contribute to the conclusion that calcium entry contributes to the observed transients is much larger than the representation of the more simplified experiments of Figure 3.
In many previously characterized systens it has been shown that calcium may be released from intracellular stores in an $\mathrm{IP}_{3}$ dependent (Ferris and Snyder, 1992) or calcium-induced calcium release-dependent manner (Lipscombe et al., 1988). Drugs that specifically address these two sources were applied. Thapsigargin, a naturally occurring sesquiterpene lactone isolated from the umbelliferous plant Thapsia garganica (Rasmussen et al., 1978), was used to deplete $\mathrm{IP}_{3}$-dependent stores by selectively blocking a Ca-ATPase pump located in the smooth endoplasmic reticulum (SER) (Thastrup et al., 1989a,b; Verma et al., 1990). Once these pools are depleted, $\mathrm{IP}_{3}$ generation does not result in calcium transients, whereas calcium-dependent calcium release stores may be activated by application of caffeine and can be blocked by ryanodine (Meissner et al., 1991). These experimental paradigms were applied to determine if intracellular calcium stores are involved in the axonal activity-induced $\left[\mathrm{Ca}^{2+}\right]_{i}$ transients.

Small $\left[\mathrm{Ca}^{?+}\right]_{i}$ transients were detected when the nerve bathing solution was changed to a calcium-free, 0.5 EGTA containing frog Ringer's, and then thapsigargin $(5 \mu \mathrm{M})$ was applied to the nerve preparation $(n=7$ ) (Fig. $4 A$ ). This was then followed by caffeine application (10 mM) (Friel and Tsien, 1992) which consistently induced a much larger $\left[\mathrm{Ca}^{2+}\right]_{i}$ transient. These results suggest that activity-associated intracellular calcium release in Inyelinating Schwann cells is more likely dependent upon calcium-activated calcium release (probably mediated by ryanodine receptor-dependent calcium stores) rather than $\mathrm{IP}_{3}$-activated calcium release.

In order to determine if there was an involvement of intracellular calcium-sensitive calcium release in the axonal activation-induced Schwann cell $\left[\mathrm{Ca}^{2+}\right]_{i}$ transient, additional pharmacological studies were carried out. Figure 5 presents a series of graphs showing the axonal activation-induced $\left[\mathrm{Ca}^{2+}\right]_{i}$ transients in a myelinating Schwann cell at two different stimulation frequencies $(10 \mathrm{~Hz}$ and $50 \mathrm{~Hz})$ followed by the addition of caffeine $(10 \mathrm{mM})$. A large $\left[\mathrm{Ca}^{2+}\right]_{i}$ transient was induced by the caffeine (Fig. 5A). The nerve was then washed with normal frog Ringer's solution until $\left[\mathrm{Ca}^{2+}\right]_{i}$ levels reached baseline. Ryanodine $(10 \mathrm{nM})$ was then added to the Ringer's and the nerve stimulated at $50 \mathrm{~Hz}$ for $5 \mathrm{~min}$. Ryanodine receptor binding is use dependent (Sutko et al., 1979; Meissner et al., 1991). Therefore, in order to check if the ryanodine-dependent calcium stores are contributing to the $\left[\mathrm{Ca}^{2+}\right]_{i}$ transients induced by axonal activity, they must first be opened to allow ryanodine to bind and alter activation of these channels. Upon stimulation in the presence of ryanodine (10 nM), a $\left[\mathrm{Ca}^{2+}\right]_{i}$ transient was observed (Fig. $5 B$ ). Upon subsequent stimulation or application of caffeine $(10 \mathrm{~mm})$, no $\left[\mathrm{Ca}^{21}\right]_{i}$ transients were observed (Fig. $5 \mathrm{C}$ ). The lack of transients was probably because the ryanodine receptor-mediated intracellular calcium stores were depleted. Taken together with the results of experiments in the absence of external $\mathrm{Ca}^{2+}$, these results suggest that most of the $\left[\mathrm{Ca}^{2+}\right]_{i}$ transients induced by axonal activity are initiated by calcium entry from an external source through the plasma membrane which then triggers the release of calcium from ryanodine receptor-mediated internal stores $\left(\mathrm{Ca}^{2+}\right.$-activated $\mathrm{Ca}^{2+}$ release).

Figure 1. Nomarski image versus fluorescence. The Nomarski images of the teased fibers reveal details of the nodal structure while the fluorescence image reveals that the fluo3-AM loading is not detectable in the axolemma. As is illustrated here, the indicator dye accumulates in the various cytoplasmic pockets of the Schwann cell including paranodal loops (small arrowheads), outer loop (large arrows), longitudinal incisors, and Schmidt-Lantermann incisors (small arrows). The left column of images was obtained with transmitted light and DIC optics (showing also the basal lamina; large arrowheads), while those on the right side are the corresponding epifluorescent images of the same myelinated fibers. 

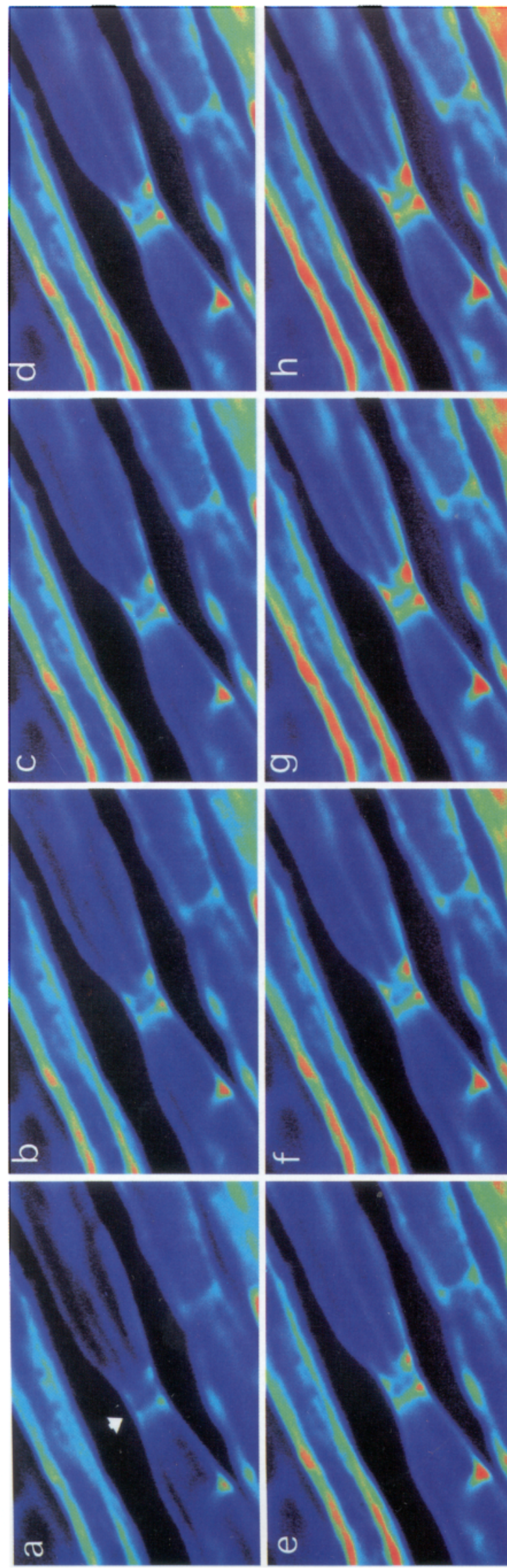
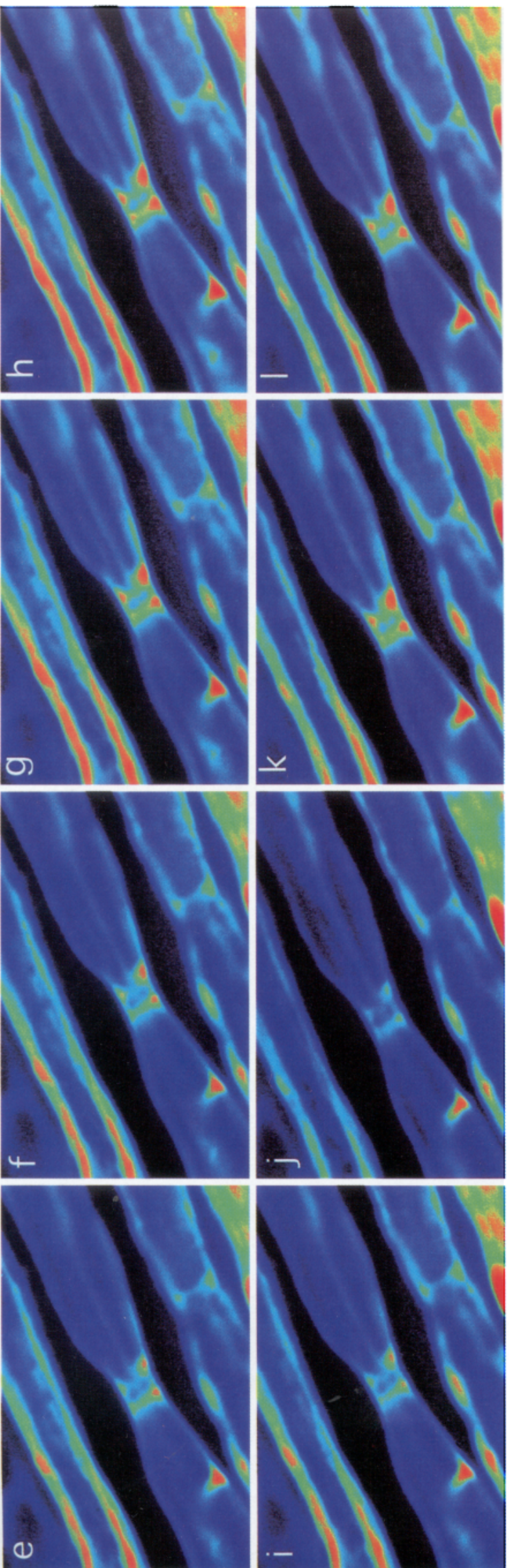

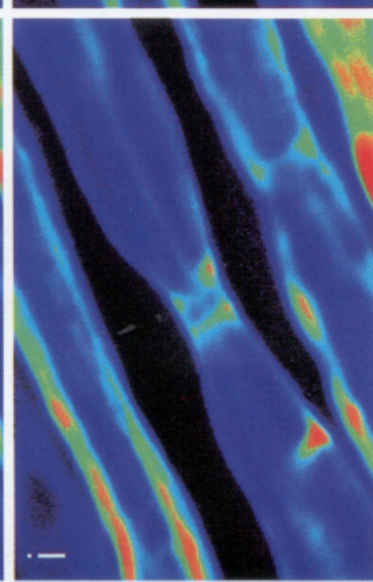

○

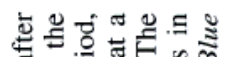

एँ

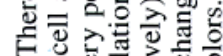

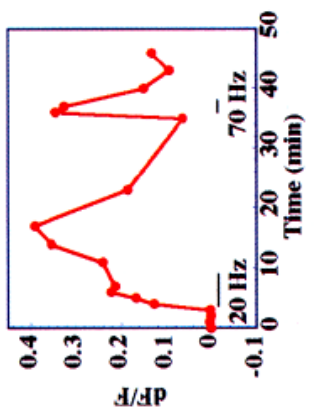

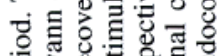

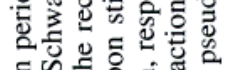

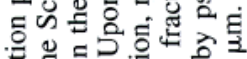

击

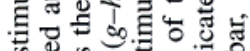

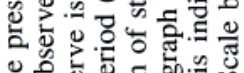

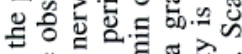

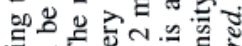

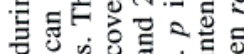

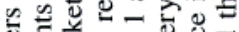

而1

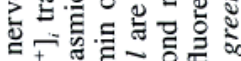

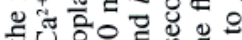

으을

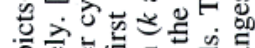

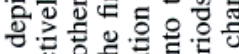

$\checkmark$ 造.

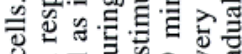

둥

들.

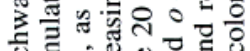

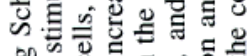

on 00 .

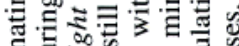

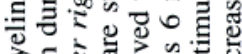

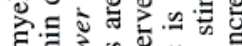

品

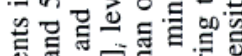

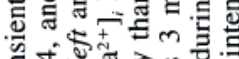

政

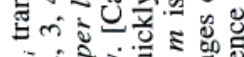

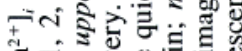

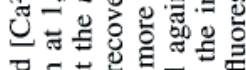

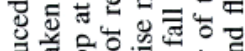

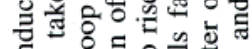

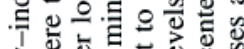

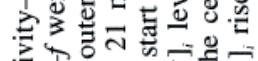

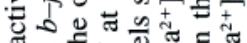

ᄃ

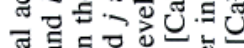

年

ख.

के

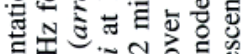

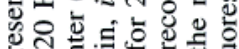

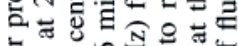

흥 명

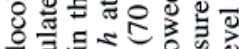

글

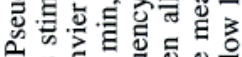

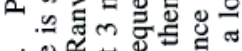

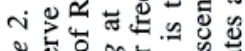

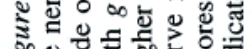

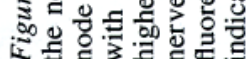


A

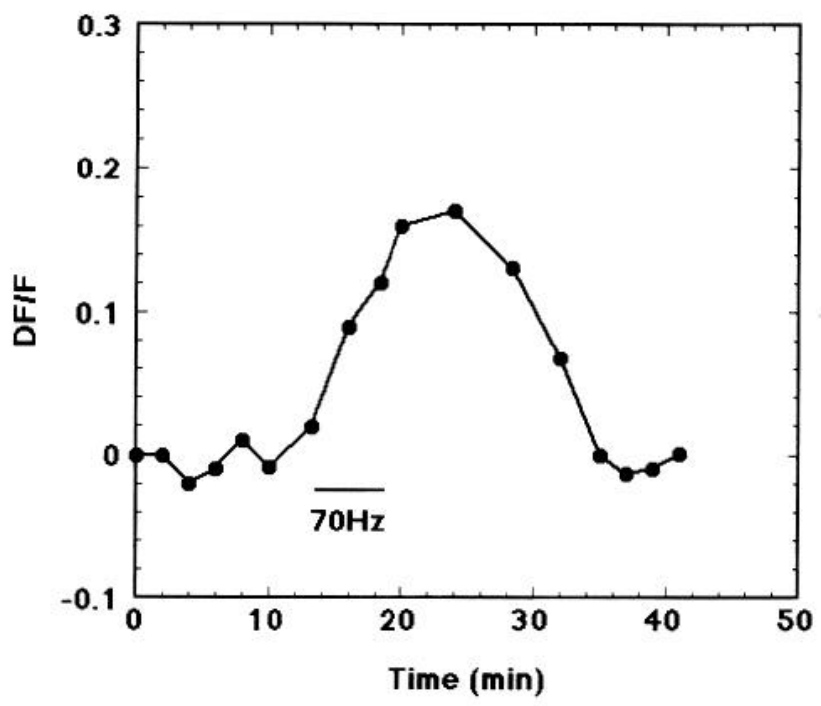

C

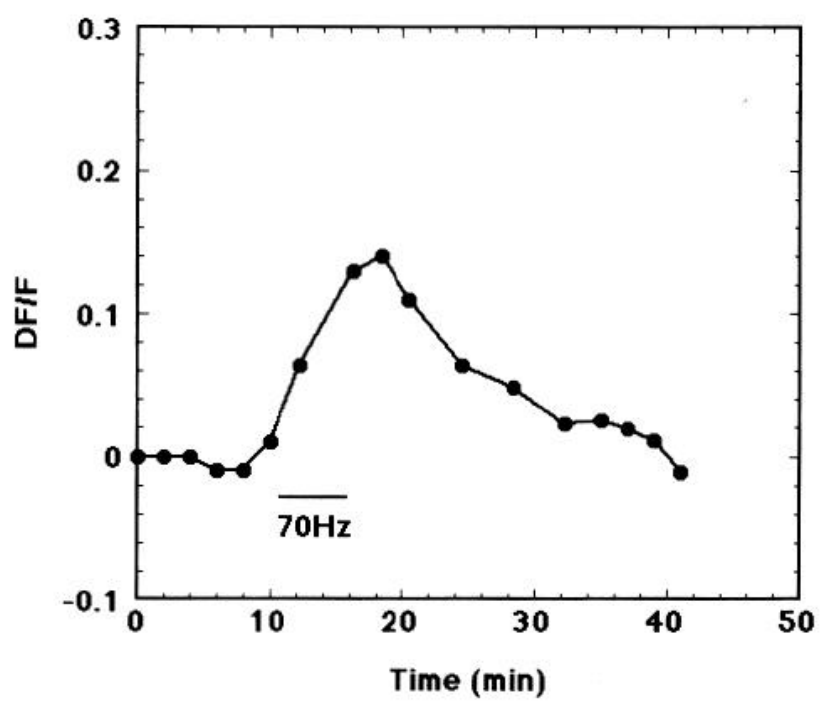

B

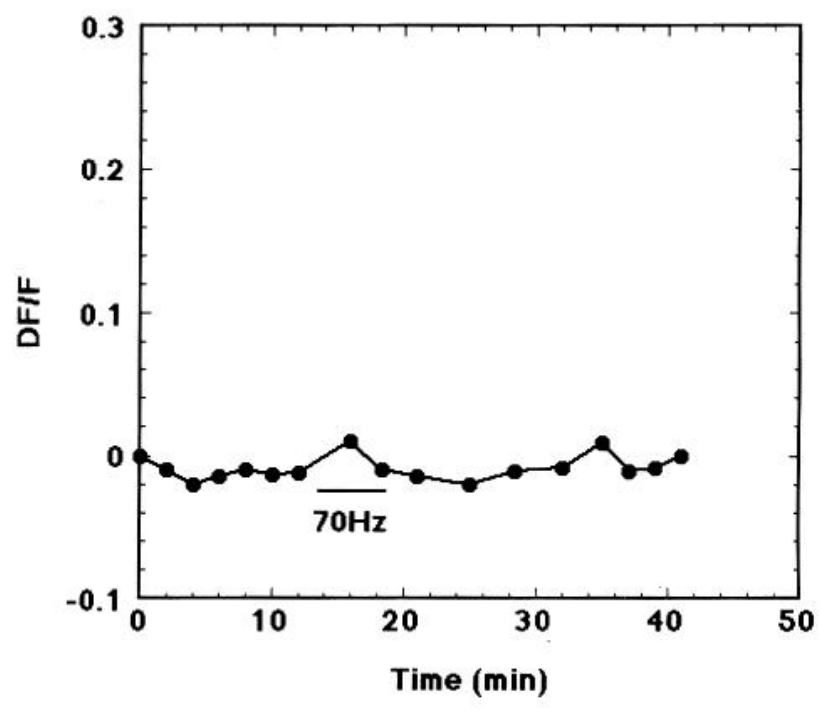

D

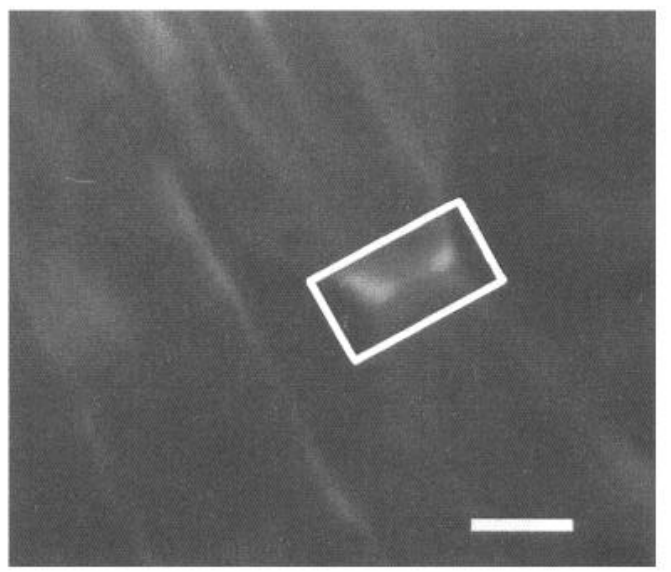

Figure 3. Extracellular calcium source for activity-induced calcium transients. This fluo3-AM-loaded nerve shows activity-induced calcium transients within various cytoplasmic pockets of its myelinating Schwann cell during stimulation at $70 \mathrm{~Hz}$ for 5 min $(A)$. Following this period of stimulation the nerve is allowed to recover for $25 \mathrm{~min}$, after which the bathing medium is changed to medium containing no calcium (and $0.5 \mathrm{~mm}$ EGTA) for 5 min before activation of the next train of impulses. No calcium transient was detected during the stimulation in media containing no calcium $(B)$. Following recovery in normal frog Ringer's solution (for $25 \mathrm{~min}$ ), the nerve is stimulated again and a calcium transient is evoked $(C$ ). These results indicate that at least part of the axonal activity-induced calcium transients in Schwann cells depends upon calcium from extracellular source. The fiber imaged in this experiment is shown in $D$. The box indicates the area that is represented graphically. Scale bar, $10 \mu \mathrm{m}$.

\section{Discussion}

The present studies have demonstrated that activity-induced calcium transients can be observed in situ in the paranodal area of peripheral nerves during axonal activity. We loaded nerves with calcium indicator and found that the dye loads into Schwann cells and could not be detected in axons. When myelinated nerve preparations loaded with calcium indicator were electrically stimulated, $\left[\mathrm{Ca}^{2+}\right]_{i}$ transients were detected in the myelinating Schwann cells. It was determined that the sources of these $\left[\mathrm{Ca}^{2+}\right]_{i}$ transients were both calcium entry through plasma membrane channels as well as release from an intracellular calcium store. The release of Schwann cell intracellular calcium associated with axonal activity appeared to be dependent upon the calcium-activated calcium release mechanisms provided by ryanodine receptors.

\section{Relationship of these observations to those of others on Schwann cell $\mathrm{Ca}^{2+}$ transients}

Other investigators reported axonal activity-induced calcium transients in Schwann cells. Jahromi and co-workers (1992) as well as Reist and Smith (1992) reported calcium transients in Schwann cells in the neuromuscular junction in response to mo- 
A

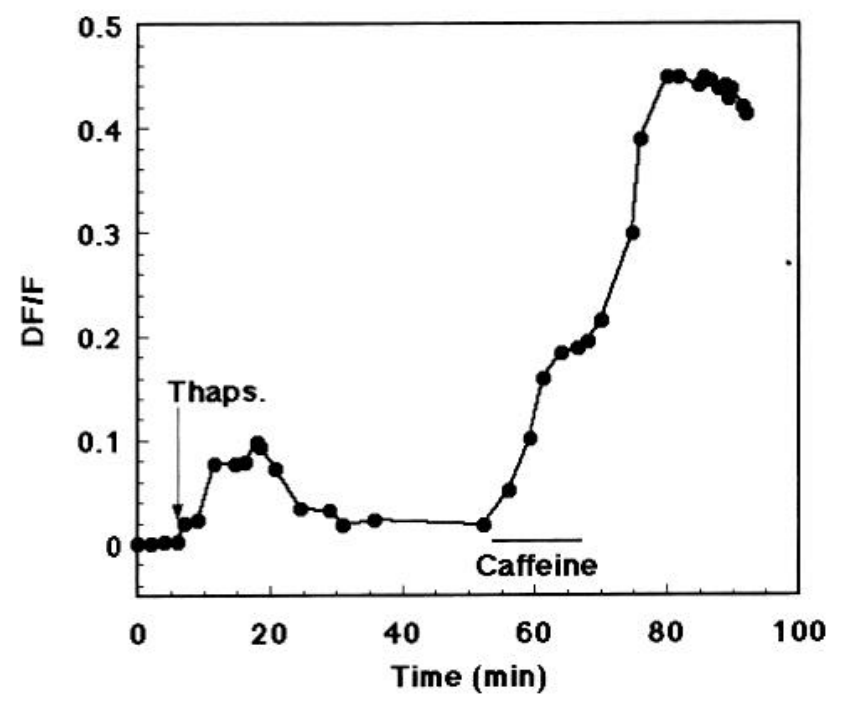

B

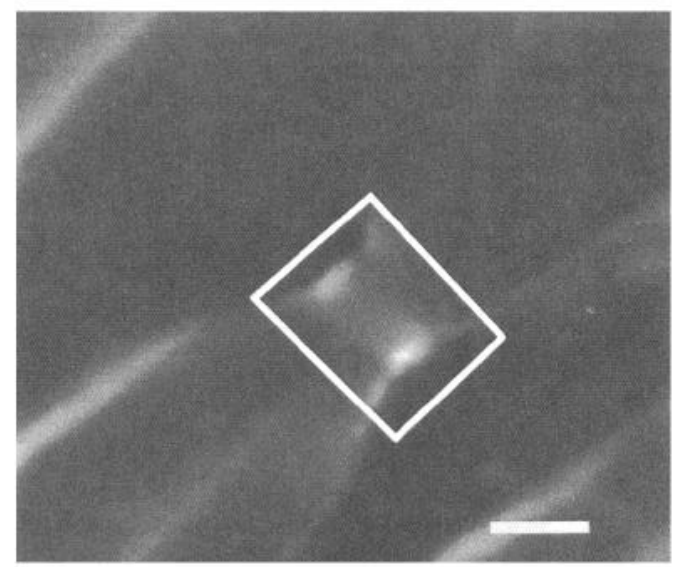

Figure 4. Qualitative comparison of release from two possible intracellular calcium stores in myelinating Schwann cells. Thapsigargin (5 $\mu \mathrm{M})$ is applied into the bathing medium of a fluo3-AM-loaded nerve in zero calcium and $0.5 \mathrm{~mm}$ EGTA. The induced calcium transient is relatively small and fast. In contrast, caffeine $(10 \mathrm{~mm})$ induces a much larger change in intracellular calcium, suggesting that myelinating Schwann cells have larger calcium-dependent calcium release stores as compared to the $\mathrm{IP}_{3}$-dependent stores. $B$ shows the image of the fiber, and the boxed area is represented graphically. Scale bar, $10 \mu \mathrm{m}$.

tor nerve stimulation. They concluded that some functions of these nonmyelinating Schwann cells are modulated by synaptic transmission and that the calcium signal observed may play a role in the maintenance or modulation of a synapse. They reported that the $\left[\mathrm{Ca}^{2+}\right]_{i}$ transients were only in the neuromuscular junction-associated nonmyelinating Schwann cells and were not observed in proximal myelinating Schwann cells. The fact that we observed transients not reported in these previous studies may be explained by a comparison of the magnitude of the fractional change in fluorescence of the present versus previous reports. Both previous studies report changes which range between $50 \%$ to several hundred percent. In contrast, the amplitude of $\left[\mathrm{Ca}^{2+}\right]_{i}$ transients in the cytoplasmic compartments of the mye- linating Schwann cells in our experiments was often less than $25 \%$ fluorescence fractional change. Furthermore, the duration of electrical stimulation used in the end-plate experiments was shorter, in the domain of seconds, while the $\left[\mathrm{Ca}^{2+}\right]_{i}$ transient we have observed arises only after much more prolonged stimulation (minutes).

Previous reports also note that $\left[\mathrm{Ca}^{2+}\right]_{i}$ transients may be evoked in nonmyelinating Schwann cells by neurotransmitter release from the nerve terminals (Jahromi et al., 1992; Reist and Smith, 1992). Nerve terminals are not present in the sciatic nerve preparation used for the studies reported here. Thus, axonal sources for neurotransmitter release are less likely. Nonetheless, the possibility that the axonal activation-associated $\left[\mathrm{Ca}^{2+}\right]_{i}$ transients in Schwann cells are evoked by nonsynaptic release of neurotransmitter along the axons must be considered. In bullfrog central and peripheral nervous system, axons were reported to release amino acid neurotransmitters upon stimulation (Wheeler et al., 1966; DeFeudis, 1971; Weinreich and Hammerchlag, 1975). In squid, giant axon release of acetylcholine has been reported to induce hyperpolarization of its ensheathing Schwann cells (Villegas, 1972, 1973; Lieberman, 1991). Krieger and Chiu (1993) suggested activity-dependent axoglia signaling mediated via neuroactive substances in the CNS of mammals. They reported that repetitive rat optic nerve activation induced calcium transients in $15-25 \%$ of glial cells in 7 -d-old rats. This activity-dependent glia activation was inhibited by TTX and occurred when nerves were stimulated in the absence of bath calcium. They suggested that the glial calcium transients were induced by substances such as glutamate or adenosine which are released from the optic nerve in a nonvesicular fashion. In their preparation, most of the axons are not yet myelinated and the authors could not determine the glial cell type from which the signals arise. Furthermore, it has not been demonstrated that activity-dependent and glutamate- or adenosine-induced calcium transients occur in the same cell, and that activity-induced signals can be blocked with glutamate antagonists. Thus, the possibility that the $\left[\mathrm{Ca}^{2+}\right]_{i}$ transients observed by us in the myelinating Schwann cells result from neurotransmitter release along activated axons remains to be detcrmined.

Since the calcium measurements that were used in this study are not ratiometric, changes in volume could lead to artifacts in fluorescence measurements. Indeed, we have observed swelling of the paranodal Schwann cell loops upon prolonged axonal activation (Wurtz and Ellisman, 1986, 1987; Raymond et al., 1990). However, swelling should increase the volume of the cell, and thus dilute the dye concentration, resulting in a reduction in fluorescence intensity. This would have been of concern to us if we had used fura 2 at the $380 \mathrm{~nm}$ excitation wavelength, since an increase in calcium at this wavelength results in reduction in fluorescence intensity. This potential problem was circumvented by the use of the calcium indicator fluo3, which responds to an increase in calcium with an increase in fluorescence. Thus, swelling and elevation in intracellular calcium concentration will result in the opposite changes in fluorescence intensity. Furthermore, in an unpublished work on swelling the frequency of the stimulation used was greater and the nerves were activated for longer periods than employed here to induce the calcium transients. Therefore, we believe it is safe to conclude that the changes in fluorescence observed in these experiments were not a result of activity-induced swelling. 
A

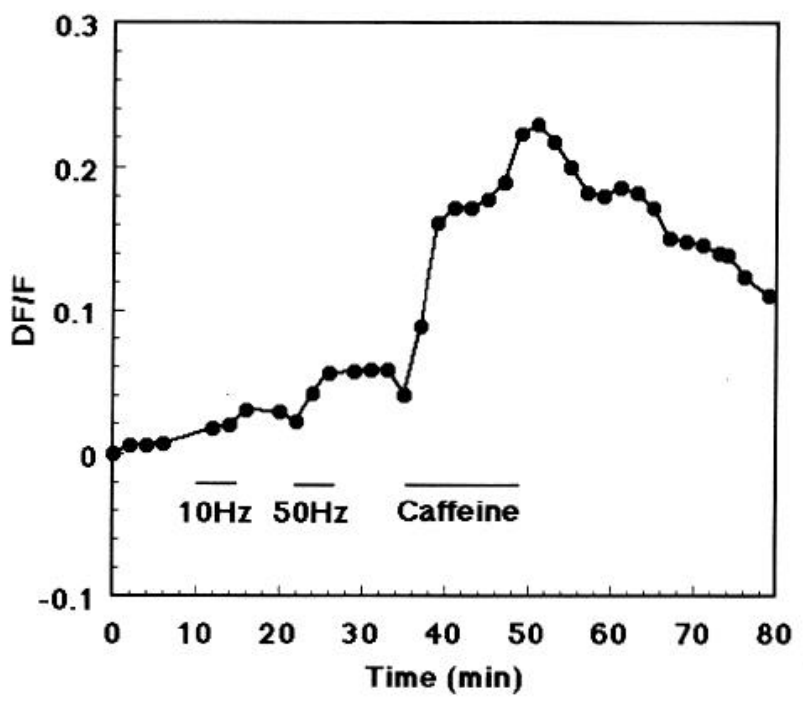

C

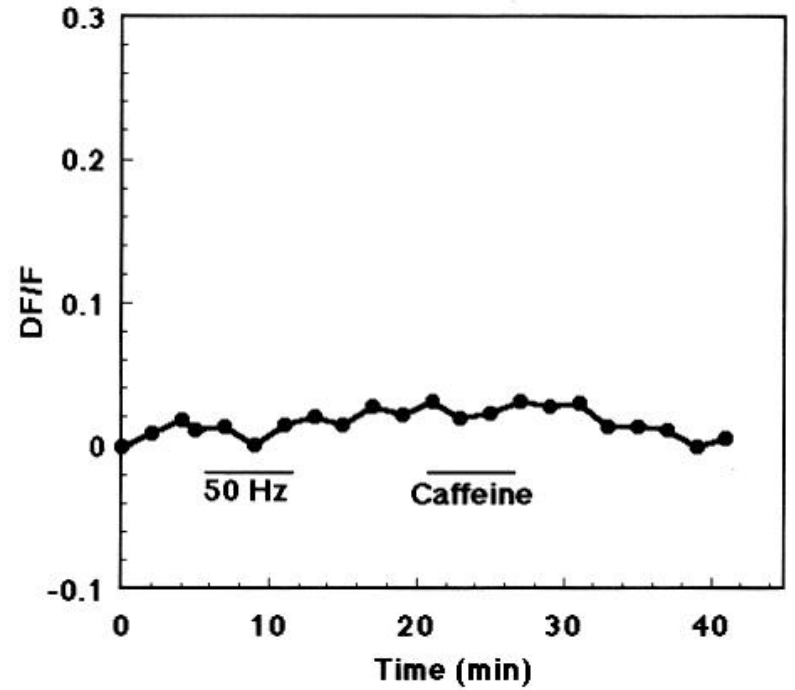

B

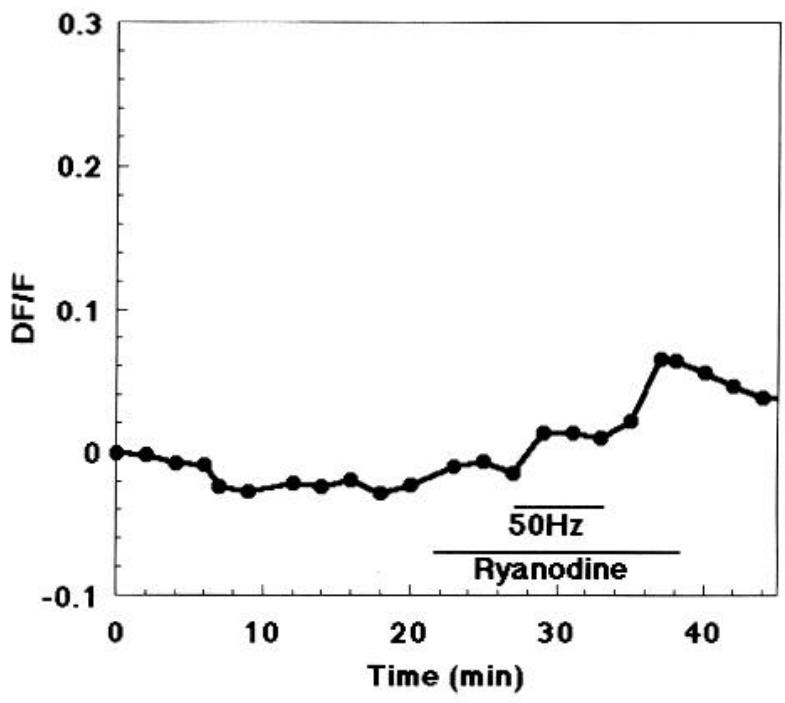

D

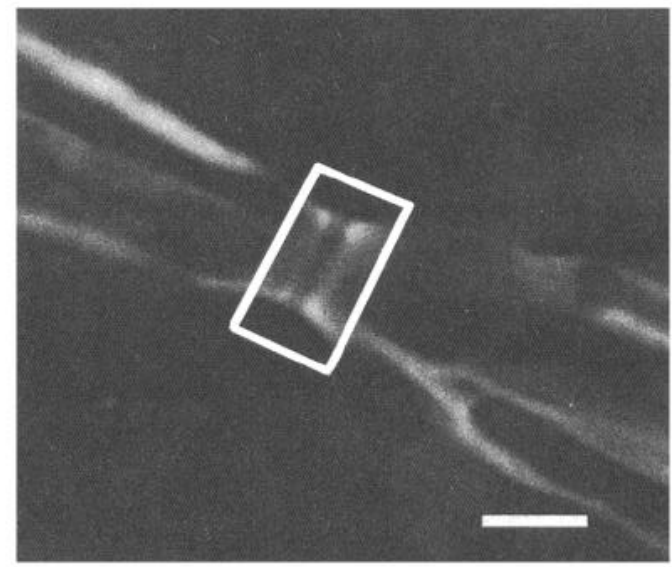

Figure 5. Intracellular source for activity-induced calcium transients. The fluo3-AM-loaded nerve shows small activity-induced calcium transients at the node of Ranvier ( $D$, boxed area) upon two consecutive 5 min stimulation periods at $10 \mathrm{~Hz}$ and $50 \mathrm{~Hz}$. Application of caffeine (10 mm) induces a larger calcium transient $(A)$. The nerve recovers for $50 \mathrm{~min}$, and then ryanodine $(10 \mathrm{nM})$ is applied and the nerve is stimulated during the presence of ryanodine to open the calcium-induced calcium releasing channels on the SER, and thus expose the receptor to ryanodine binding $(B)$. The nerve is then allowed to recover for another $50 \mathrm{~min}$ and is stimulated again and exposed to $10 \mathrm{~mm}$ caffeine, but no further calcium transients are detected. These results indicate that a ryanodine receptor-mediated calcium-induced calcium release-type calcium store may be involved in the axonal activity-induced calcium transients in Schwann cells. Scale bar, $10 \mu \mathrm{m}$.

\section{Are $K^{+}$channels involved?}

Potassium movements through $\mathrm{K}^{+}$channels may be linked to these Schwann cell $\mathrm{Ca}^{2+}$ transients. Although clearly only parts of the physiological machinery that determine how the nodal complex responds to repetitive activation were examined in this study, the data described in this report further the development of a working hypothesis for functioning of the nodal complex. It is well established that following sufficient depolarization sodium enters the axon through voltage-gated sodium channels at the nodal area, while axonal potassium exits the axon mostly in the paranodal and internodal regions (see summaries in Waxman and Ritchie, 1985, and Black et al., 1990). According to measurements from several laboratories, the space between the paranodal axolemma and the myelinating glia is very limited, with a volume of only about $0.47 \mu^{3}$ (Rydmark and Berthold, 1983). With such a small volume, potassium accumulation, per spike, has been predicted to rise to as great as $9.0 \mu \mathrm{M}$ at the paranode (Chiu, 1991). Such an elevation in $\left[\mathrm{K}^{+}\right]_{0}$ in this region would be expected to depolarize the adjacent region of axolemma and inactivate a subpopulation of the $\mathrm{Na}^{+}$channels at the node, ultimately resulting in a reduction in current density for propagation of the subsequent action potential (Adelman et al., 
1973; Hassan and Lieberman, 1988). To prevent such an increase in $\left[\mathrm{K}^{+}\right]_{\text {, }}$, within these restricted intercellular paranodal compartments, we and others presume that potassium is siphoned into the paranodal Schwann cell loops through potassium channels (Shrager et al., 1985; Van Erp et al., 1990).

Functional diversity of $\mathrm{K}^{+}$channels is great enough to accommodate many different schemes for ionic fluxes in Schwann cells. However, only a few types of $\mathrm{K}^{+}$channels are confirmed to be expressed by these cells including Kv1.1 and Kv1.5 (Mi et al., 1993), two voltage-dependent channels. In order to understand the vectoral movements of $\mathrm{K}^{+}$ions in this system, it is crucial to determine the detailed distribution of both $\mathrm{K}^{+}$channels and $\mathrm{Na}^{+} / \mathrm{K}^{+}$pumps. Some information has already been obtained showing concentrations of Kv1.5 in the Schwann paranodal region (Mi et al., 1993) and the $\alpha 1$ isoform of the $\mathrm{Na}^{+} / \mathrm{K}^{+}$ ATPase on the Schwann cell microvilli (Ariyasu et al., 1985).

\section{A provisional model}

We suggest that potassium efflux from axons following the action potential induces a depolarization of the paranodal loops, which results in calcium entry from external sources (possibly voltage-dependent calcium channels). The entering calcium may then trigger release of calcium from ryanodine-dependent stores, causing a further increase in $\left[\mathrm{Ca}^{2+}\right]_{i}$. In order to balance the suspected excess of $\left[\mathrm{K}^{+}\right]_{i}$, water probably enters the loops and reduces the ionic concentration. The swelling of the paranodal region after repetitive activation which has been observed (Wurtz and Ellisman, 1986, 1987; V. Lev-Ram and M. H. Ellisman, unpublished results) may be a consequence of such water entry. When frog nonmyelinating fibers are exposed to moderately high levels of extracellular potassium, swelling is seen in the Schwann cell and not in the axons (Ho et al., 1981). This could suggest a normally existing mechanism in Schwann cclls which leads to swelling when extracellular potassium is elevated. We suspect that marked conduction slowing observed following repetitive activation results from the load of potassium ions exiting the axon and exceeding the capacity of the Schwann cell machinery to buffer it away from the paranodal and nodal regions. After the capacity of the system is saturated, the extracellular potassium concentration may rise in the vicinity of the axolemma, depolarizing the membrane and thus inactivating a greater proportion of the voltage-dependent sodium channels of the nodal axolemma. This would result in a decrement in the inward sodium current at the node upon its subsequent activation. The net impact of this would be to increase the threshold and slow conduction velocity. Thus, in this model, axon and Schwann cells would modulate each other.

We conclude from these observations that although the involvement of myelinating glia in saltatory conduction of the nerve impulse is well established, the role of these cells in managing the distribution of ions and metabolites at nodes of Ranvier has not been fully defined experimentally. We hope to gain a new understanding of the role of the paranodal complex. Definition of its functions may provide insights into liability of this site in inflammatory processes such as multiple sclerosis.

\section{References}

Adelman WJ Jr, Palti Y, Senft JP (1973) Potassium ion accumulation in a periaxonal space and its effect on the measurement of membrane potassium ion conductance. J Membr Biol 13:387-410.

Amedee T, Fllie E, Dupony R, Vincent JD (1991) Voltage-dependent calcium and potassium channels in Schwann cells cultured from dorsal root ganglia of the mouse. J Physiol (Lond) 441:35-56.
Ariyasu RG, Nichol JA, Ellisman MII (1985) Localization of sodium/ potassium adenosine triphosphatase in multiple cell types of the murine nervous system with antibodies raised against the enzyme from kidney. J Neurosci 5:2581-2596.

Black JA, Kocsis JD, Waxman SG (1990) Ion channel organization of the myelinated fiber. Trends Neurosci 13:48-54.

Carley LR, Raymond SA (1987) Comparison of the after-effects of impulse conduction on threshold at nodes of Ranvier along single frog sciatic axons. J Physiol (Lond) 386:503-527.

Chiu SY (1991) Functions and distribution of voltage-gated sodium and potassium channels in mammalian Schwann cells. Glia 4:541558 .

DeFeudis FV (1971) Effects of electrical stimulation on the efflux of L-glutamate from peripheral nerve in vitro. Exp Neurol 30:291-296.

Dyck PJ, Thomas PK, Griffin JW, Law PA, Poduslo JF (1993) Peripheral neuropathy. Philadelphia: Saunders.

Ellisman MH, Palmer DE, Andre MP (1987) Diagnostic levels of ultrasound may disrupt myelination: Exp Neurol 98:78-92.

Endres W, Grafe P, Bostock H, ten Bruggencate G (1986) Changes in extracellular $\mathrm{pH}$ during electrical stimulation of isolated rat vagus nerve. Neurosci Lett 64:201-205.

Ferris CD, Snyder SH (1992) IP3 receptors. Ligand-activated calcium channels in multiple forms. Adv Second Messenger Phosphoprotein Res 26:95-107.

Friel DD, Tsien RW (1992) A caffeine- and ryanodine-sensitive $\mathrm{Ca}^{2+}$ store in bullfrog sympathetic neurones modulates cffects of $\mathrm{Ca}^{2+} \mathrm{cn}$ try on $\left[\mathrm{Ca}^{2+}\right]_{i}$. J Physiol (Lond) 450:217-246.

Halter JA, Clark JW Jr (1991) A distributed-parameter model of the myelinated nerve fiber. J Theor Biol 152:569-571.

Halter JA, Clark JW Jr (1993) The influence of nodal constriction on conduction velocity in myelinated nerve fibers. Neuroreport 4:89-92.

Hassan S, Lieberman EM (1988) Studies of axon-glial cell interactions and periaxonal $\mathrm{K}^{+}$homeostasis-II. The effect of axonal stimulation, cholinergic agents and transport inhibitors on the resistance in series with the axon membrane. Neuroscience 25:961-969.

Ho KC, Friede RL, Garancis J, Sato KA (1981) The morphological changes in unmyelinated peripheral nerve fibers exposed to low sodium and high potassium concentrations. J Neurol Sci 50:299-238.

Howe JR, Ritchie JM (1988) Two types of potassium current in rabbit cultured Schwann cells. Proc R Soc Lond [Biol] 235:19-27.

Jahromi BS, Robitaille R, Charlton MP (1992) Transmitter release increases intracellular calcium in perisynaptic Schwann cells in situ. Neuron 8:1069-1077.

Krieger S, Chiu SY (1993) Calcium signaling of glial cells along mammalian axons. J Neurosci 13:4229-4245.

Lev-Ram V, Grinvald A (1986) $\mathrm{Ca}^{2+}$ - and $\mathrm{K}^{+}$-dependent communication between central nervous system myelinated axons and oligodendrocytes revealed by voltage-sensitive dyes. Proc Natl Acad Sci USA 83:6651-6655.

Lev-Ram V, Grinvald A (1987) Activity-dependent calcium transients in central nervous system myelinated axons revealed by the calcium indicator Fura2. Biophys J 52:571-576.

Lieberman EM (1991) Role of glutamate in axon-Schwann cell signaling in the squid. Ann NY Acad Sci 633:448-457.

Lillie RS (1925) Factors affecting transmission and recovery in the passive iron nerve model. J Gen Physiol 7:473-485.

Lipscombe D, Madison DV, Poenie M, Reuter H, Tsien RW, Tsien RY (1988) Imaging of cytosolic $\mathrm{Ca}^{2+}$ transients arising from $\mathrm{Ca}^{2+}$ stores and $\mathrm{Ca}^{2+}$ channels in sympathetic neurons. Neuron 1:355-365.

Meissner G, Lai FA, Anderson K, Xu L, Liu QY, Herrmann-Frank A, Rousseau E, Jones RV, Lee HB (1991) Purification and reconstitution of the ryanodine- and caffeine-sensitive $\mathrm{Ca}^{2+}$ release channel complex from muscle sarcoplasmic reticulum. Adv Exp Med Biol 304:241-256.

Mi H, Inman I, Deerinck T, Simpliciano V, Ellisman MH, Schwař TL (1993) Identification and localization of $\mathrm{K}^{+}$channels in myelinated peripheral nerve. Soc Neurosci Abstr 19:704.

Mugnaini E, Osen KK, Schnapp B, Friedrich VL Jr (1977) Distribution of Schwann cell cytoplasm and plasmalemmal vesicles (caveolae) in peripheral myelin sheaths. An electron microscopic study with thin sections and freeze-fracturing. J Neurocytol 6:647-668.

Murray N, Steck AJ (1984) Impulse conduction regulates myelin basic protein phosphorylation in rat optic nerve. J Neurochem 43:243-248.

Ranvier LM (1878) Leçons sur l'histologie du système nerveux. Paris: Savy. 
Raymond SA, Steffensen SC, Ellisman MH (1990) Observation of node of Ranvier structure during sustained impulse activity in single frog axon. Soc Neurosci Abstr 29.7.

Reist NE, Smith SJ (1992) Neurally evoked calcium transients in terminal Schwann cells at the neuromuscular junction. Proc Natl Acad Sci USA 89:7625-7629.

Rydmark M, Berthold CH (1983) Electron microscopic serial section analysis of nodes of Ranvier in lumbar spinal roots of the cat: a morphometric study of nodal compartments in fibres of different sizes. J Neurocytol 12:537-565.

Shrager P, Chiu SY, Ritchie JM (1985) Voltage-dependent sodium and potassium channels in mammalian cultured Schwann cells. Proc Natl Acad Sci USA 82:948-952

Stoops JK, Schroeter JP, Bretaudiere JP, Olson NH, Baker TS, Strickland DK (1991) Structural studies of human alpha 2-macroglobulin: concordance between projected views obtained by negative stain and cryoelectron microscopy. J Struct Biol 106:172-178.

Sutko JL, Willerson JT, Templeton GH, Jones LR, Besch HR Jr (1979) Ryanodine: its alterations of cat papillary muscle contractile state and responsiveness to inotropic interventions and a suggested mechanism of action. J Pharmacol Exp Ther 209:37-47.

Thastrup O, Cullen PJ, Drobak BK, Hanley MR, Dawson AP (1989a) Thapsigargin a tumor promoter discharges intracellular $\mathrm{Ca}^{2+}$ stores by specific inhibition of the endoplasmic reticulum $\mathrm{Ca}^{2+}$-ATPase. Proc Natl Acad Sci USA 87:2466-2470.

Thastrup O, Dawson AP, Scharff O, Foder B, Cullen PJ, Drobak BK Bjerrum PJ, Christensen SB, Hanley MR (1989b) Thapsigargin a novel molecular probe for studying intracellular calcium release and storage. Agents Actions 27:17-23.

Uhrik B, Stampfli R (1981) Ultrastructural observations on nodes of Ranvier from isolated single frog peripheral nerve fibres. Brain Res 215:93-101

Van Erp MG, Van Dongen AM, Van den Berg RJ (1990) Voltage- dependent action of valproate on potassium channels in frog node of Ranvier. Eur J Pharmacol 184:151 161.

Verkhratsky A, Hoppe D, Kettenmann H (1991a) Single $\mathrm{K}^{+}$channel properties in cultured mouse Schwann cells: conductance and kinetics. J Neurosci Res 28:200-209.

Verkhratsky A, Hoppe D, Kettenmann H (1991b) $\mathrm{K}^{+}$channel properties in cultured mouse Schwann cells: dependence on extracellular $\mathrm{K}^{+}$. J Neurosci Res 28:210-216.

Verma A, Hirsch DJ, Hanley MR, Thastrup O, Christensen SB, Snyder SH (1990) Inositol trisphosphate and thapsigargin discriminate endoplasmic reticulum stores of calcium in rat brain. Biochem Biophys Res Commun 172:811-816.

Villegas .I (1972) Axon-Schwann cell interaction in the squid nerve fibre. J Physiol (Lond) 225:275-296.

Villegas J (1973) Effects of tubocurarine and eserine on the axonSchwann cell relationship in the squid nerve fibre. J Physiol (Lond) 23:193-208

Waxman SG, Ritchie JM (1985) Organization of ion channels in the myelinated nerve fiber. Science 288:1502-1507.

Weinreich D, Hammerschlag R (1975) Nerve impulse-enhanced release of amino acids from non-synaptic regions of peripheral and central nerve trunks of bullfrog. Brain Res 84:137-142.

Wheeler DD, Boyarsky LL, Brooks WH (1966) The release of amino acids from nerve during stimulation. J Cell Physiol 67:141-147.

Wiley-Livingston CA, Ellisman MH (1982) Return of axonal and glial membrane specializations during remyelination after tellurium-induced demyelination. J Neurocytol 1 1:65-80.

Wurtz CC, Ellisman MH (1986) Alterations in the ultrastructure of peripheral nodes of Ranvier associated with repetitive action potential propagation. J Neurosci 6:3133-3143.

Wurtz CC, Ellisman MH (1987) Activity associated ultrastructural changes in peripheral nodes of Ranvier are independent of fixation. Exp Neurol 101:87-106. 